\title{
Migration flow and its impact on tuberculosis notification in Portugal
}

\section{Abstract}

Introduction: Tuberculosis notification in Portugal has decreased in the last few years. As a consequence of the economic crisis, emigration has increased and immigration has decreased. Immigrants are a risk group for tuberculosis. Most emigrants are 20-44 years old and belong to the age group most affected by tuberculosis.

Objective: To describe the decrease in tuberculosis notification in Portugal over the last years from a demographical point of view.

Methods: Mathematical analysis was performed to quantify the effect of the migration movements (separately and simultaneously) on tuberculosis notification in Portugal from 2008 to 2014 . We calculated the estimated tuberculosis notification for each year during the period of study: 1) fixing immigration rate and tuberculosis rate in immigrants at 2008 values; 2) fixing emigration rate and tuberculosis rate in emigrants at 2008 values; 3 ) fixing both phenomenons at 2008 values.

Results: The differences between the observed and the estimated numbers were small ( $\leq 0.5$ cases $/ 100000$ inhabitants).

Discussion: Impact of the migration movements on tuberculosis notification rate does not seem to be significant when analyzed for each phenomenon individually and simultaneously, by our model. This might mean that we have to concentrate our efforts in other risk factors for tuberculosis.

Keywords: emigration, immigration, tuberculosis

\section{Introduction}

Since WHO declared tuberculosis (TB) a global emergency, many efforts have been made worldwide to decrease TB incidence. ${ }^{1}$ In Portugal, a TB National Program was implemented in 1995 and in 2006 the "STOP TB strategy" was launched to delineate specific goals and strengthen the struggle towards the end of TB. ${ }^{2,3}$

Eight years later, in 2014, Portugal reached the threshold of low incidence, registering 20 new cases per 100000 inhabitants. ${ }^{4}$ Despite this, it remains the highest incidence country in the Western Europe and some areas still have an intermediate incidence. Lisbon and Oporto are the districts with the highest incidence. ${ }^{4,5}$ 
Homeless people, drug users, prisoners and migrants are at increased risk of developing TB. These groups concentrate in urban settings and their numbers tend to have an impact on TB. ${ }^{6,7,8,9,10}$ This work concentrates solely on the migrant movements' effect on TB. In fact, in many European countries, most cases of tuberculosis occur within the immigrant population. About $26.8 \%$ of TB cases reported in the European Union (EU) and European Economic Area countries are of foreign origin. ${ }^{5}$ Therefore, migrants from high incidence countries have a considerable impact on the tuberculosis burden in low incidence countries. ${ }^{5,10}$ Increased risk of TB in this group might be related to higher exposure in the country of origin and/or worse socioeconomic conditions, comparing to the resident population. ${ }^{11}$

As opposed to other European countries, like Iceland, Cyprus, Norway or Sweden, where more than $70 \%$ of tuberculosis cases occur in foreign born individuals, in Portugal, this group represents only about $16 \%$ of cases. ${ }^{6,10,12}$ Nevertheless, TB incidence among immigrants in Portugal is much higher than in non-immigrants and it has been increasing. ${ }^{13}$

As a consequence of the economic crisis, in the last few years, an increasing number of individuals have left the country to live abroad. Portugal is the EU country with the largest number of emigrants per capita. ${ }^{14}$ In 2014, the number of emigrants had risen to the double, compared to 2008 . The majority are young adults, aged 20 to 44 years old, that left Portugal seeking for better working and living conditions abroad. ${ }^{15,16}$ This age group overlaps with the one most affected by TB, between 25 and 54 years old. ${ }^{4}$

The main aim of this study is to describe the decrease in TB in Portugal over the last years purely from a demographical point of view. As such, the authors quantify the effect of the migration movements (immigration and emigration) on the TB notification in Portugal (from 2008 to 2014).

\section{Methods}

Data and sources

Data on tuberculosis notification were collected from the Portuguese Tuberculosis Surveillance System (SVIG-TB) coordinated by the Directorate General of Health (DGH) during the seven year period ranging from 2008 to 2014. Data on migration movements for the period of study (2008-2014) were collected from Immigration and Borders Service Statistics and Statistics Portugal, the public Portuguese entity responsible for the official statistical information and included: 1) the absolute number of resident immigrants in each year; 2) the absolute number of immigrants per year; 3) the absolute number of 
emigrants per year; 4) the migration balance, which refers to the difference between the number of individuals entering and leaving the country, per year.

For the purpose of this paper, TB cases with no information on the country of origin were excluded from the analysis.

As this was a retrospective study and used routinely collected surveillance data, neither ethical approval nor informed consent were required.

\section{Mathematical analysis}

The impact of the migration movements on the TB burden was initially addressed separately for immigration and emigration, and simultaneously afterwards. The separate analysis allowed for the study of the influence of each migration phenomenon in isolation. Firstly, the expected number of TB cases per 100000 inhabitants for year $t(2008,2009$, ..., 2014) under a steady situation of immigration (i.e., keeping both the number of immigrants and the number of TB-cases among immigrants at their 2008 values) was computed by:

$$
\text { Expected TB cases }(t)=\frac{T B_{N I}(t)+T B_{I}\left(t_{0}\right)}{P(t)-E(t)+I\left(t_{0}\right)} \times 100000
$$

Here, $T B_{N I}(t)$ denotes the number of TB-cases within the non-immigrant resident population in year $t, T B_{I}\left(t_{0}\right)$ denotes the number of TB-cases within the immigrant population in $t_{0}=2008$, and $P(t)$ (resp. $E(t), I\left(t_{0}\right)$ ) represents the number of Portuguese individuals (resp. emigrants, immigrants) in year $t$ (resp. $t, t_{0}$ ). Clearly, $P(t)-E(t)+I\left(t_{0}\right)$ corresponds to the total number of individuals resident in Portugal in year $t$.

Then, for each year, the expected number was compared with the observed number of TB-cases (including different annual counts for the number of immigrants and TB-cases among immigrants). The magnitude of the differences allowed for the evaluation of the impact of the immigration process on the TB incidence.

The model evaluating the impact of the emigration on TB in Portugal followed a similar reasoning; keeping both the number of emigrants and the number of TB-cases among emigrants at its 2008 value, the expected number of TB cases for year $t$ per 100000 inhabitants was calculated by

108

$$
\text { Expected } T B \text { cases }(t)=\frac{T B_{N I}(t)+\left(T B_{E}(t)-T B_{E}\left(t_{0}\right)\right)+T B_{I}(t)}{P(t)-E\left(t_{0}\right)+I(t)} \times 100000
$$


where the number of TB-cases among emigrants in year $t, T B_{E}(t)$, assumed the same per-capita rate as $T B_{N I}(t)$, namely

$$
T B_{E}(t)=E(t) \times \frac{T B_{N I}(t)}{P(t)-E(t)}
$$

Indeed, had the TB-emigrants in year $t$ stayed in the country and the difference $T B_{E}(t)-$ $T B_{E}\left(t_{0}\right)$ would have been accounted for in the total number of cases within national territory. The magnitude of the differences between observed and expected counts allowed for the evaluation of the impact of the emigration process on the TB incidence.

The study of the simultaneous effect of immigration and emigration combined the previous two equations. Under a steady scenario of immigration and emigration, the expected number of TB cases for year $t$ per 100000 inhabitants would be

$$
\text { Expected TB cases }(t)=\frac{T B_{N I}(t)+\left(T B_{E}(t)-T B_{E}\left(t_{0}\right)\right)+T B_{I}\left(t_{0}\right)}{P(t)-E\left(t_{0}\right)+I\left(t_{0}\right)} \times 100000 .
$$

Finally, the relative annual fluctuations observed within the total number of Portuguese residents were compared with the relative annual decreases in the number of TB-cases. For each variable, the relative annual fluctuation between year $t+1$ and year $t$ was computed as

$$
\frac{\operatorname{Number}(t+1)-N u m b e r(t)}{\text { Number }(t)} \text {. }
$$

\section{Results}

From 2009 to 2013 there was a steady annual increase in the number of emigrants and essentially a decrease in the number of immigrants. The years 2008 and 2014 have slightly contradicted this trend.

138 Until 2010, the number of immigrants per year was higher than the number of emigrants. From 2011 to 2014, there was an inversion in the migration flow, and the number of emigrants exceeded the number of immigrants, thus turning the migration balance negative (table 1). 
The number of TB cases has been consistently decreasing since 2008. Cases occurring

143 in immigrants represented $13.8 \%$ of all cases in $2008,15.2 \%$ in 2009 and remained

144 stable at about $16 \%$ since 2010 . Immigrants have a much higher notification rate of TB

145 than the Portuguese individuals (table 2).

146 Similar to the TB notification rate, the total resident population in Portugal, has essentially 147 decreased over 2008-2014 (with the exception of a slight increase from 2008 to 2009).

148 However, the relative annual decrease on the number of residents was lower than the 149 decrease on the TB numbers (table 3).

150 As shown in table 1, from 2008 to 2014 there were relatively few immigrants entering 151 Portugal. Fixing both the immigration rate and the TB rate among immigrants at their

1522008 values, and considering the variation on emigration that has actually occurred, 153 we've estimated the number of TB cases per 100000 inhabitants for each studied year 154 (table 4). The differences between the observed and the estimated numbers were 155 residual, ranging from more 0.27 cases/100000 inhabitants in 2010 to less 0.49 156 cases/100000 inhabitants in 2014.

157 On the other hand, emigration rose significantly during the period of study (table 1), which 158 could have influenced the TB rate in the country to go lower.

159 The official number of TB cases in emigrants leaving the country in 2008 was $1604.87 / 100000$ inhabitants. Assuming that this rate remained constant along 2008-2014 161 and that the total number of emigrants did not change either along that period, we 162 estimated annual numbers for TB in Portugal. The observed numbers were only slightly 163 higher than their estimates. The differences were even smaller than those found for the immigration impact (<0.1 cases $/ 100000$ inhabitants) (table 5). When looking at both migration movements at the same time, the observed TB rate was again identical to the estimated TB rate (differences between less 0.43 cases/100000

\section{Discussion}

The number of TB cases has been decreasing in Portugal (notification rate was $27.8 / 100000$ inhabitants in 2008 vs 21.8 cases/100000 inhabitants in 2014). Since 2009, the resident population has also been decreasing, but at a slower pace, as shown in table 3. As for that, the decreasing number of TB cases cannot only be due to the reduction in the resident population.

176 Between 2008 and 2010, the number of immigrants exceeded the number of emigrants 177 (positive migration balance). Since 2011 until 2014, migration balance turned negative. Moreover, TB rate has been consistently higher among immigrants compared to the 
native population ( $>90$ cases $/ 100000$ inhabitants vs $18.3-23.9$ cases $/ 100000$ inhabitants). The percentage of TB cases in this group has risen from $13.2 \%$ in 2008 to $15.2 \%$ in 2009 and remained at about $16 \%$ since 2010 . This model allowed us to evaluate the impact of the immigration on the TB rate. It showed that, since 2011, as immigration is decreasing, there is a tendency to a lower number of TB cases. However, the differences are very small, representing less than 1 case per 100000 inhabitants, so the impact does not seem to be significant.

A decrease in TB incidence has been the trend in the whole WHO European Region over the last years, where it has fallen by $5.2 \%$ each year, since $2005 .^{5}$

Efforts have been made to achieve lower TB rates in Europe, even in low incidence countries. Out of 31 low incidence countries evaluated, more than half $(54.8 \%)$ reported to have a dedicated national TB programme. ${ }^{17}$

Despite this global trend and even though we failed to demonstrate a significant impact of the immigration global decrease on TB rate, immigrants are still a risk group as in many of their origin countries, infectious diseases, such as TB, are still an important cause of death and morbidity. ${ }^{18}$ In low incidence countries, the impact of immigration on the burden of TB has been largely studied. ${ }^{10,19,20,21}$ Addressing risk groups is one of the key strategies against TB. ${ }^{8,22}$ In the recently published action framework of the WHO towards TB elimination in low incidence countries ${ }^{23}$ strategies involving migrants are mentioned in three of the eight priority action areas: 1) to address the most vulnerable and hard-to-reach groups; 2) to address special needs of migrants and crossborder issues and 3) to undertake screening for active TB and latent tuberculosis infection (LTBI) in TB contacts and selected highrisk groups, and provide appropriate treatment. Many efforts have been made to detect TB and LTBI among migrants. ${ }^{12}$ Some EU countries have implemented screening of migrants before, or at entry. ${ }^{24}$ Underwood et al. compared contact tracing with new entrant screening in London and found the former to be more effective, as it identifies families and communities at high risk. ${ }^{21}$ With the recent increase in the number of immigrants coming to Europe as refugees (rising from about 219000 in 2014 to more than one million in 2015), TB control in this group is also a concern. ${ }^{25,26}$ Regarding this matter, the ERS/WHO European Region has performed a study in order to document the policies and practices of low and intermediate TB incidence European countries with regards to detection and management of TB and latent TB infection among this vulnerable group. ${ }^{26}$

213 In countries where most cases of TB occur in foreign born individuals or where incidence 214 in this group is increasing, despite a decreasing TB rate, as it occurs in Portugal, policies on this subject are of great importance. 
216 As for the emigration increase over the period of study, our model showed very little

217 differences between the number of observed and expected cases $(<0.1$ cases $/ 100000$

218 inhabitants each year). The fact that the differences between observed and expected

219 cases were smaller than those found for the immigration impact can mean that the

220 increase in emigration that we observed over 2008-2014 has not significantly impact the

221 national TB rate.

222 We assumed the TB rate in emigrants to be similar to the TB rate in the Portuguese

223 individuals that stayed in the country. However, we do not know if these individuals had

224 other risk factors for TB or if they became more vulnerable for TB when they moved

225 abroad.

226 Torres Redondo et al. ${ }^{27}$ retrospectively analyzed the Portuguese emigrants diagnosed

227 with TB when returning to the country, in the Northern Region in 2014. Most cases

228 (76.3\%) had moved to low TB incidence countries and had lived there for more than 2 229 years (median time of $\mathbf{4 2 . 0}$ months), which could suggest that exposure to TB could have 230 already occurred in the foreign country. About $67 \%$ shared housing with work colleagues.

231 These data suggest that risk for TB might increase when emigrants leave the country as 232 they might experience harder living conditions and economic adversity. Nevertheless,

233 had they stayed in the country they might have been unemployed which also accounts 234 as a risk factor for TB. ${ }^{28}$

235 Despite the lack of knowledge about this group, our model failed to demonstrate an 236 impact of emigration on TB notification rate.

237 Individually, the migration movements did not influence TB rate when analyzed by our 238 model, so we tried to look at the impact of both movement altogether. Differences were 239 again very small ( $<0.5$ cases/100000 inhabits each year), so, even when combined, 240 migration movements do not seem to largely influence TB notification rate.

241 This might mean that we have to concentrate our efforts in other risk factors. Sousa et 242 al. ${ }^{28}$ recently found HIV to be the factor with this highest impact: an increase of $10 \mathrm{HIV}$ 243 notifications per 100000 inhabitants was associated with a rise of 2 new TB cases per 244100000 inhabitants. Also, an increase of 1000 unemployed subjects per 100000 245 inhabitants was associated with one new case of TB per 100000 inhabitants.

246 Apart from HIV infection, poor living and working conditions, which can facilitate TB 247 transmission and risk factors that impair host's defense, like malnutrition, smoking, 248 diabetes, alcohol abuse and indoor air pollution have been pointed out as major 249 determinants. ${ }^{29,30,31,32}$

250 Silicosis also increases the risk of TB by 2.8-39 times. ${ }^{33,34}$ Silico-TB can be a challenging 251 diagnosis and treatment must be longer. ${ }^{35}$

252 Preventive strategies that target these factors might have an important impact on TB 
burden.

These risk factors also add to the risk for TB in the migrant population. Paulino $\mathrm{J}$ et al. ${ }^{13}$ found that foreign born patients were more likely to be HIV positive, to be employed, homeless or live in shelters. Reducing HIV infection and providing better living conditions might have an even greater impact on TB among migrants. A study performed in Italy by Ingrosso $L$ et al. also showed that HIV infection is three times more frequent in foreign born people affected by TB than among Italians. ${ }^{36}$

Altogether, these factors represent areas of intervention towards TB elimination and should all be addressed in national and international TB programmes. ${ }^{23}$

In this work, the authors tried to understand the impact of two demographic factors - the migration movements and the decrease in the total number of residents- on the burden of TB in Portugal over the 7-year period 2008-2014. As such, other risk factors such as HIV infection, homelessness or overcrowded housing were assumed to remain constant over that period.

In conclusion, the changing pattern of migration in Portugal over the period of study (2008-2014) does not seem to have had a significant impact on the TB notification rate.

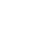

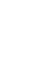

\section{References}

1- World Health Organization. WHO declares tuberculosis a global emergency. Sozial-und Präventivmedizin, July 1993, Volume 38, Issue 4, pp 251-252 
2- Direcção Geral da Saúde. Programa Nacional de Luta contra a Tuberculose. Ministério da Saúde, Comissão Nacional de Luta contra a Tuberculose. 1995

3- Organização Mundial de Saúde. A Estratégia Stop TB, 2006. http://www.who.int/tb/publications/2006/stoptb_strategy_por.pdf.

Last accessed: 25/09/2016

4- Direcção Geral da Saúde. Diniz A, Duarte R, Bettencourt J, Melo T, Gomes M, Oliveira O. Portugal - Infeção VIH, SIDA e Tuberculose em números - 2015. Novembro de 2015. www.dgs.pt. Last accessed: 25/09/2016

5- European Centre for Disease Prevention and Control/WHO Regional Office for Europe. Tuberculosis surveillance and monitoring in Europe 2016. Stockholm: European Centre for Disease Prevention and Control, 2016

6- Odone A, Tillmann T, Sandgren A, Williams G, Rechel B, Ingleby D. Tuberculosis among migrant populations in the European Union and the European Economic Area. European Journal of Public Health, 2014; Vol. 25, No. 3, 506-512

7- van Hest NA, Aldridge RW, de Vries G, et al. . Tuberculosis control in big cities and urban risk groups in the European Union: a consensus statement. Euro Surveill. 2014;19(9): pii=20728

8- European Centre for Disease Prevention and Control. Guidance on tuberculosis control in vulnerable and hard-to-reach populations. Stockholm: European Centre for Disease Prevention and Control, 2016

9- Franco I, Sousa P, Gomes M, Oliveira A, Gaio AR, Duarte R. Social profile of the highest tuberculosis incidence areas in Portugal. Rev Port Pneumol 2016; 22(1):50-56

10-Ködmön C, Zucs P, van der Werf MJ. Migration-related tuberculosis: epidemiology and characteristics of tuberculosis cases originating outside the European Union and European Economic Area, 2007 to 2013. Euro Surveill 2016;21(12)

11-Hargreaves JR, Boccia D, Evans CA, Adato M, Petticrew M, Porter JDH. The Social Determinants of Tuberculosis: From Evidence to Action. American journal of public health $2011 ; 101(4): 654-662$

12-Mulder C, Klinkenberg E, Manissero D. Effectiveness of tuberculosis contact tracing among migrants and the foreign born population. Euro Surveill 2009; 14(11):pii=19153.

13-Paulino J, Martins A, Machado M, Gomes M, Gaio AR, Duarte R. Tuberculosis in native- and foreign-born populations in Portugal. Int $\mathrm{J}$ Tuberc Lung Dis 20(3):357-362 
14-Pires RP, Pereira C, Azevedo J, Ribeiro AC. Observatório da Emigracão. Emigracão Portuguesa- Relatório Estatístico 2014, Lisboa. Observatório da Emigração e Rede Migra, CIES-IUL, ISCTE-IUL.

15-Instituto Nacional de Estatística. https://www.ine.pt/xportal/xmain?xpgid=ine_main\&xpid=INE; Last accessed: $25 / 09 / 2016$

16-Filipe Correia MI. Análise dos efeitos da crise das dívidas soberanas na migração do sul para o norte da Europa: o caso Português. Trabalho final de Mestrado em Economia Internacional e Estudos Europeus. Outubro de 2015

17- D'Ambrosio L, Masoud D, Tadolini M, et al. Tuberculosis elimination: theory and practice in Europe. Eur Respir J. 2014 May; 43(5):1410-20.

18-Brian D, Gushulak BD, MacPherson DW. Globalization of infectious diseases: the impact of migration. Clinical Infectious Diseases 2004; 38:1742-8

19-Buonora N, Chiavarini M, Salmasi L, Giaimo M, Minelli L. Impact of immigration on burden of Tuberculosis in Umbria: a low-incidence Italian region with high immigrants rates. Journal of Preventive Medicine and Hygiene 2013;54(1):29-34.

20-Pareek M, Greenaway C, Noori T, Munoz J, Zenner D. The impact of migration on tuberculosis epidemiology and control in high-income countries: a review. BMC Medicine 2016;14:48

21-Underwood BR, White VLC, Baker T, Law M, Moore-Gillon JC. Contact tracing and population screening for tuberculosis- who should be assessed? J Public Health Med 2003; 25(1):59-61.

22-The End TB Strategy Global Strategy and targets for tuberculosis prevention, care and control after 2015. November 2015. http://www.who.int/tb/post2015_TBstrategy.pdf Last accessed: 25/09/2016

23-Lönnroth K, Battista Migliori T, Abubakar I, et al. Towards tuberculosis elimination: an action framework for low-incidence countries. Eur Respir J. 2015 Apr; 45(4): 928-52

24- Pareek M, Baussano I, Abubakar I, Dye C, Lalvani A. Evaluation of Immigrant Tuberculosis Screening in Industrialized Countries. Emerg Infect Dis 2012;18(9):1422-1429

25-Solovic I, Abubakar I, Sotgiu G, et al. Standard operating procedures for tuberculosis care. Eur Respir J. 2017 Jun 1;49 (6)

26-Dara M, Solovic I, Sotgiu G, et al. TB care among refugees arriving in Europe: a ERS/WHO Europe Region Survey of Current Practices. Eur Respir J 2016; 48(3):808-17 
27-Torres Redondo M, Carvalho C, Correia AM, Duarte R. Tuberculosis en los portugueses residentes en el extranjero. Arch Bronconeumol. 2016. http://dx.doi.org/10.1016/j.arbres.2016.09.015

28-Sousa P, Oliveira A, Gomes M, Gaio AR, Duarte R. Longitudinal clustering of tuberculosis incidence and predictors for the time profiles: the impact of HIV. Int J Tuberc Lung Dis 2016;20(8):1027-32

29-Lönnroth K, Jaramillo E, Williams BG, Dye C, Raviglione M. Drivers of tuberculosis epidemics: The role of risk factors and social determinants; Soc Sci Med 2009 Jun;68(12):2240-6

30-Harling G, Ehrlich R, Myer L. The social epidemiology of tuberculosis in South Africa: a multilevel analysis; Soc Sci Med. 2008;66(2):492-505

31- Francisco J, Oliveira O, Felgueiras Ó, Gaio AR, Duarte R. How much is too much alcohol in tuberculosis? Eur Respir J 2017 Jan 18;49(1).

32- Cordeiro da Costa J, Oliveira O, Baía L, Gaio R, Correia-Neves M, Duarte R. Prevalence and factors associated with diabetes mellitus among tuberculosis patients: a nationwide cohort. Eur Respir J 2016 Jul;48(1):264-8

33- Calvert GM1, Rice FL, Boiano JM, Sheehy JW, Sanderson WT. Occupational silica exposure and risk of various diseases: an analysis using death certificates from 27 states of the United States. Occup Environ Med 2003;60:122---9

34-Hnizdo E, Murray J. Risk of pulmonary tuberculosis relative to silicosis and exposure to silica dust in South African gold miners [published erratum appears in Occup Environ Med 1999 Mar;56(3):215-6]. Occupational and Environmental Medicine 1998;55(7):496-502

35- V Melo, L Baía, A Rita Gaio, R Duarte. Silicosis, tuberculosis time bomb? Rev Port Pneumol 2016; Nov - Dec;22(6):355-357

36- Ingrosso L, Vescio F, Giuliani M, et al. Risk Factors for Tuberculosis in ForeignBorn People (FBP) in Italy: A Systematic Review and Meta-Analysis. PLoS ONE 2014; 9(4): e94728 
401

402

403

404

405

406

407

408

409

410

411

412

413

414

415

416

417

418

419

\begin{tabular}{|lllllll|}
\hline Year & $\begin{array}{l}\text { Total } \\
\text { resident } \\
\text { population } \\
\text { N }\end{array}$ & $\begin{array}{l}\text { Immigrant } \\
\text { resident } \\
\text { population N }\end{array}$ & $\begin{array}{l}\text { Emigrants } \\
\text { N }\end{array}$ & $\begin{array}{l}\text { Immigrants }^{\mathrm{a}} \\
\mathrm{N}\end{array}$ & $\begin{array}{l}\text { Migration }_{\text {balance }^{\mathrm{b}}} \\
\text { Portuguese } \\
\text { Individuals }^{\mathrm{c}} \\
\mathrm{N}\end{array}$ \\
\hline $\mathbf{2 0 0 8}$ & 10563014 & 440277 & 20357 & 29718 & 9361 & 10553653 \\
\hline $\mathbf{2 0 0 9}$ & 10573479 & 454191 & 16899 & 32307 & 15408 & 10558071 \\
\hline $\mathbf{2 0 1 0}$ & 10572721 & 445262 & 23760 & 27575 & 3815 & 10568906 \\
\hline $\mathbf{2 0 1 1}$ & 10542398 & 436822 & 43998 & 19667 & -24331 & 10566729 \\
\hline $\mathbf{2 0 1 3}$ & 10487289 & 417042 & 51958 & 14606 & -37352 & 10524641 \\
\hline $\mathbf{2 0 1 4}$ & 10427301 & 401320 & 53786 & 17554 & -36232 & 10463533 \\
\hline & 10374822 & 395195 & 49572 & 19516 & -30056 & 10404878 \\
\hline
\end{tabular}


Table 1. Migration movements. M: male; F: female. a: Immigrants entering the country each year b: Migration balance: immigrants - emigrants c: Portuguese individuals $=$ total resident population + emigrants - immigrants

\begin{tabular}{|c|c|c|c|c|c|c|c|c|}
\hline Year & $\begin{array}{l}\text { TB } \text { cases }^{\mathrm{a}} \\
\mathrm{N}\end{array}$ & $\begin{array}{l}\text { TB } \\
\text { rate }^{b}\end{array}$ & $\begin{array}{l}\text { TBPI } \\
N\end{array}$ & $\begin{array}{l}\text { TBPI } \\
\text { rate }^{d}\end{array}$ & $\begin{array}{l}\mathrm{TBl}^{\mathrm{e}} \\
\mathrm{N}\end{array}$ & $\% \mathrm{TBI}$ & $\begin{array}{l}\text { TBI } \\
\text { rate }^{f}\end{array}$ & $\begin{array}{ll}\text { TBcases } & \text { missing } \\
\text { origin N (\%) }\end{array}$ \\
\hline 2008 & 2967 & 27,8 & 2523 & 23,9 & 410 & $13,8 \%$ & 93,1 & $34(1,2)$ \\
\hline 2009 & 2869 & 27,1 & 2432 & 23,0 & 437 & $15,2 \%$ & 96,2 & $0(0)$ \\
\hline 2010 & 2714 & 25,6 & 2273 & 21,5 & 438 & $16,1 \%$ & 98,4 & $3(0,1)$ \\
\hline 2011 & 2609 & 24,7 & 2203 & 20,9 & 404 & $15,5 \%$ & 92,5 & $2(0,1)$ \\
\hline 2012 & 2606 & 24,6 & 2176 & 20,7 & 408 & $15,7 \%$ & 97,8 & $22(0,8)$ \\
\hline 2013 & 2399 & 22,8 & 1989 & 19,0 & 393 & $16,4 \%$ & 97,9 & $17(0,7)$ \\
\hline 2014 & 2264 & 21,8 & 1904 & 18,3 & 357 & $15,8 \%$ & 90,3 & $3(0,1)$ \\
\hline
\end{tabular}

Table 2. Tuberculosis numbers. M: male; F: female; TB: tuberculosis a: as documented in SVIG-TB; includes the cases for which the country of origin is missing.

b: TB rate: TB cases (excluding TB cases with missing origin) per 100000 inhabitants

c: TBPI: TB cases in Portuguese individuals = TB cases - TB cases in immigrants - TB cases with missing origin

d: TBPI rate: TBPI cases per 100000 inhabitants

e: TBI: TB cases in immigrants

f: $T B I$ rate: $T B I$ cases per 100000 resident immigrants

\begin{tabular}{|llll|}
\hline Period & Resident population decrease & Tuberculosis cases decrease \\
& & -0.03 & 450 \\
\hline $\mathbf{2 0 0 8 - 2 0 0 9}$ & 0.00 & -0.05 & 437 \\
\hline $\mathbf{2 0 0 9 - 2 0 1 0}$ & 0.00 & -0.04 & 438 \\
\hline $\mathbf{2 0 1 0 - 2 0 1 1}$ & 0.00 & 0.00 & 439 \\
\hline $\mathbf{2 0 1 1 - 2 0 1 2}$ & -0.01 & -0.08 & 440 \\
\hline $\mathbf{2 0 1 2 - 2 0 1 3}$ & -0.01 & -0.06 & 442 \\
\hline $\mathbf{2 0 1 3 - 2 0 1 4}$ & -0.01 & & \\
\hline
\end{tabular}

Table 3. Variation of the total number of residents and TB notification rate

\begin{tabular}{|llll|}
\hline Year & $\begin{array}{l}\text { Observed number of } \\
\text { TB cases per 100000 } \\
\text { in inhabitants (0) }\end{array}$ & $\begin{array}{l}\text { Expected TB cases } \\
\text { per } \\
\text { inhabitants (E) }\end{array}$ & \\
\hline $\mathbf{2 0 0 8}$ & 27,77 & NA & NA \\
\hline $\mathbf{2 0 0 9}$ & 27,13 & 26,89 & 0,24 \\
\hline $\mathbf{2 0 1 0}$ & 25,64 & 25,37 & 0,27 \\
\hline $\mathbf{2 0 1 1}$ & 24,73 & 24,76 & -0.03 \\
\hline $\mathbf{2 0 1 2}$ & 24,64 & 24,62 & 0,02 \\
\hline $\mathbf{2 0 1 3}$ & 22,84 & 22,98 & -0.14 \\
\hline
\end{tabular}


446 Table 4. Differences between observed and estimated numbers of TB cases when 447 evaluating the impact of the immigration on the TB notification rate. O: observed; E: 448 expected

\begin{tabular}{|llll|}
\hline Year & $\begin{array}{l}\text { Observed number of } \\
\text { TB cases per 100000 } \\
\text { in inhabitants (0) }\end{array}$ & $\begin{array}{l}\text { Estimated } \\
\text { cases per 100000 } \\
\text { inhabitants (E) }\end{array}$ & O-E \\
\hline $\mathbf{2 0 0 8}$ & 27,77 & NA & NA \\
\hline $\mathbf{2 0 0 9}$ & 27,13 & 27,13 & 0,00 \\
\hline $\mathbf{2 0 1 0}$ & 25,64 & 25,64 & 0,00 \\
\hline $\mathbf{2 0 1 1}$ & 24,73 & 24,71 & 0,02 \\
\hline $\mathbf{2 0 1 2}$ & 24,64 & 24,62 & 0,02 \\
\hline $\mathbf{2 0 1 3}$ & 22,84 & 22,82 & 0,02 \\
\hline $\mathbf{2 0 1 4}$ & 21,79 & 21,77 & 0,02 \\
\hline
\end{tabular}

450 Table 5. Differences between observed and estimated numbers of TB cases when evaluating the impact of the emigration on the TB notification rate. O: observed; $E$ : estimated

\begin{tabular}{|llll|}
\hline Year & $\begin{array}{l}\text { Observed number of } \\
\text { TB cases per 100000 } \\
\text { in inhabitants (0) }\end{array}$ & $\begin{array}{l}\text { Estimated } \\
\text { cases per 100000 } \\
\text { inhabitants (E) }\end{array}$ & \\
\hline $\mathbf{2 0 0 8}$ & 27,77 & NA & NA \\
\hline $\mathbf{2 0 0 9}$ & 27,13 & 26,89 & 0,24 \\
\hline $\mathbf{2 0 1 0}$ & 25,64 & 25,36 & 0,28 \\
\hline $\mathbf{2 0 1 1}$ & 24,73 & 24,71 & 0,02 \\
\hline $\mathbf{2 0 1 2}$ & 24,63 & 24,55 & 0,08 \\
\hline $\mathbf{2 0 1 3}$ & 22,84 & 22,91 & $-0,07$ \\
\hline $\mathbf{2 0 1 4}$ & 21,79 & 22,22 & $-0,43$ \\
\hline
\end{tabular}

454 Table 6. Differences between observed and estimated numbers of TB cases when 455 evaluating simultaneously the impact of immigration and emigration on the TB notification rate. $\mathrm{O}$ : observed; $\mathrm{E}$ : estimated 